\title{
Assessing the Attractiveness of Three Baits for Roof Rats in California Citrus Orchards
}

\author{
Kallista N. Wales ${ }^{1}$, Ryan Meinerz ${ }^{2}$ and Roger A. Baldwin ${ }^{2, *}$ \\ 1 Department of Animal Biology, University of California, Davis, CA 95616, USA; knwales@ucdavis.edu \\ 2 Department of Wildlife, Fish, \& Conservation Biology, University of California, Davis, CA 95616, USA; \\ rmeinerz@ucdavis.edu \\ * Correspondence: rabaldwin@ucdavis.edu
}

Citation: Wales, K.N.; Meinerz, R.; Baldwin, R.A. Assessing the Attractiveness of Three Baits for Roof Rats in California Citrus Orchards. Agronomy 2021, 11, 2417. https:// doi.org/10.3390/agronomy11122417

Academic Editor: Radek Aulický

Received: 6 November 2021

Accepted: 25 November 2021

Published: 27 November 2021

Publisher's Note: MDPI stays neutral with regard to jurisdictional claims in published maps and institutional affiliations.

Copyright: (c) 2021 by the authors. Licensee MDPI, Basel, Switzerland. This article is an open access article distributed under the terms and conditions of the Creative Commons Attribution (CC BY) license (https:// creativecommons.org/licenses/by/ $4.0 /)$.

\begin{abstract}
Roof rats (Rattus rattus) are common pests of tree fruit and nut orchards in California Tracking tunnels are an effective and practical tool for monitoring changes in roof rat numbers in orchard systems, but they rely on the use of attractive baits to draw in rats to the tracking surface. The identification of baits that are both attractive and readily available would be of great assistance for monitoring changes in roof rat numbers within agricultural fields. Therefore, we tested the attractiveness of a soft bait (Liphatech Rat and Mouse Attractant ${ }^{\mathrm{TM}}$ ), a wax block (Liphatech NoTox ${ }^{\mathrm{TM}}$ ), peanut butter, and a control (i.e., no bait applied) to roof rats when applied within tracking tunnels. We did not observe a difference in visitation to any of the tested attractants, although all attractants yielded greater visitation rates than control tunnels. However, tracking tunnels without any attractant were still visited at a relatively high rate, indicating the tracking tunnel is attractive to roof rats. As such, monitoring tools that provide shelter may increase detectability, although this would need to be verified. Regardless, all three food-based lures we tested increased the attractiveness of tracking tunnels and could be used to increase visitation to these monitoring devices.
\end{abstract}

Keywords: attractant; citrus; peanut butter; Rattus rattus; roof rat; soft bait; tracking tunnel; wax block

\section{Introduction}

Exotic, invasive mammals and birds result in approximately US $\$ 46$ billion in damage and associated control costs annually in the U.S., with rat damage and control constituting more than half of this amount (US\$27 billion annually) [1]. Roof rats (Rattus rattus) are a particularly destructive rat species. Their presence can substantially affect native ecosystems and agriculture due to their adaptability and high reproductive outputs, and they carry many diseases and parasites that are of substantial concern to native wildlife, humans, and domestic animals [2-5]. Roof rats can be particularly damaging in tree fruit and nut crops through the direct consumption of fruits and nuts, through girdling of branches leading to branch mortality, by chewing on irrigation lines and microsprinklers, and through food safety concerns associated with fecal contamination [5-8]. Efficacious and cost-effective strategies are needed to reduce damage from this invasive species.

Current tools for managing roof rats include toxicants, fumigants, traps, exclusion, repellents, fertility control, and habitat management, among others [9]. Understanding when to implement these management tools relies largely on the ability to track changes in roof rat activity over time. Furthermore, our ability to determine the efficacy of a given management strategy requires the use of a monitoring tool to assess roof rat activity before and after treatment. Common monitoring strategies for roof rats include chewing indices (e.g., chew cards and wax blocks), snap and live trapping, remote-triggered cameras, and tracking tunnels [10-13]. Although tracking tunnels are not used to assess densities of rodents, they are still quite useful as a monitoring tool given their ease of operation and the fact that they require the user to only determine presence or absence within a given tunnel. These are both important attributes if farmers and pest control professionals are 
going to implement such a monitoring approach. However, the effectiveness of tracking tunnels will depend at least in part on the use of bait that is highly attractive to roof rats to ensure high visitation rates, yet is easily obtainable by the applicator.

One common approach is to use non-toxic commercial attractants to determine changes in rodent activity. For example, non-toxic wax blocks have been used to monitor changes in rodent numbers either through their use as a chewing index $[10,14]$ or as an attractant to other monitoring tools (e.g., remote-triggered cameras) [12]. Non-toxic sachets of soft bait are increasingly used to monitor rat abundance in commensal settings [15], and they may be an effective attractant in agricultural fields as well. Alternatively, peanut butter is a common bait used to attract many rodent species, including roof rats $[13,16]$, in part due to its high fat content [17]. All three of these potential attractants are readily available and easy to implement for farmers, pest control professionals, and researchers, thereby making them convenient candidates for monitoring roof rats in orchards. Therefore, we established a replicated trial using a commercial non-toxic wax monitoring block, a commercial non-toxic soft bait, and peanut butter to determine which of these baits proved most attractive for roof rats in citrus orchards when used within tracking tunnels.

\section{Materials and Methods}

We conducted this study across six different sites (three in lemons, two in oranges, and one in a mixture of lemons and oranges) in Tulare and Kern counties, California, USA, from January through April 2021. Fruit and leaves are on the trees year-round, so we anticipate our results will reflect roof rat responses to the tested attractants throughout the year. At each site, we established a $385-\mathrm{m} \times 385-\mathrm{m}$ plot. Within each plot, we placed corrugated plastic tracking tunnels $(60 \mathrm{~cm} \times 15 \mathrm{~cm} \times 13 \mathrm{~cm}$, Pest Control Research LP, Christchurch, NZ) following a $10 \times 10$ grid structure $(n=100$ total tracking tunnels) with each tunnel location separated by approximately $35 \mathrm{~m}$ (Figure 1), although for one site, we were only able to place six tracking tunnels in the last line due to that line intersecting a parking area for field personnel ( $n=96$ tracking tunnels). We placed the first tracking tunnel for each line approximately $35 \mathrm{~m}$ from the outside perimeter of each plot to reduce any edge effect. One of three attractants (NoTox ${ }^{\mathrm{TM}}$ wax blocks (Liphatech, Inc., Milwaukee, WI, USA), Rat and Mouse Attractant ${ }^{\mathrm{TM}}$ soft baits (Liphatech, Inc., Milwaukee, WI, USA), and Jif ${ }^{\circledR}$ creamy peanut butter (The JM Smucker Company, Orrville, OH, USA); hereafter referred to as wax blocks, soft baits, and peanut butter, respectively) or a control (i.e., no attractant) were assigned to each tracking tunnel location following a stratified random sampling approach where each attractant or control option was cycled through (see Figure 1 for an example of the plot layout). This resulted in 25 of each attractant type being used per field site, except for the one site where we had a truncated final line. For this site, we replicated each attractant across 24 tracking tunnels. We randomly selected a different order for the attractants at each site to reduce the likelihood that the location within the orchards had an impact on visitation by roof rats.

For each tracking tunnel, we applied ink at the center of a tracking card designed to stain the roof rat's paws when it walked through the tunnel. For the first field site, we placed attractants in the center of the inkpad, and then placed the cards into the tunnel. However, when checking the tracking tunnels at the end of the trial period, we occasionally found that the wax blocks and soft baits would be missing without any footprints left on the tracking card. We were unsure if this was because the attractant slid out of the tunnel or if it was due to a roof rat removing the bait without leaving footprints. To reduce the likelihood of attractants disappearing in future trial periods, we impaled the bottom of the tracking tunnels and tracking cards with Grip Rite \#12 $\times 3.18 \mathrm{~cm}$ metal, square-cap, roofing nails (Prime Source Building Products, Inc., Irving, TX, USA). We then impaled the wax blocks or soft baits on these nails. This modification was effective at keeping these attractants from disappearing at the final 5 trial sites. We did not use the nails in the peanut butter or control tracking tunnels. Because we were uncertain if missing attractants from the first plot were due to animal removal or due to bait sliding out of the tracking tunnels, 
we removed all tracking tunnels from analysis when the attractants were missing, and no footprints were left behind (a total 15 tunnels).

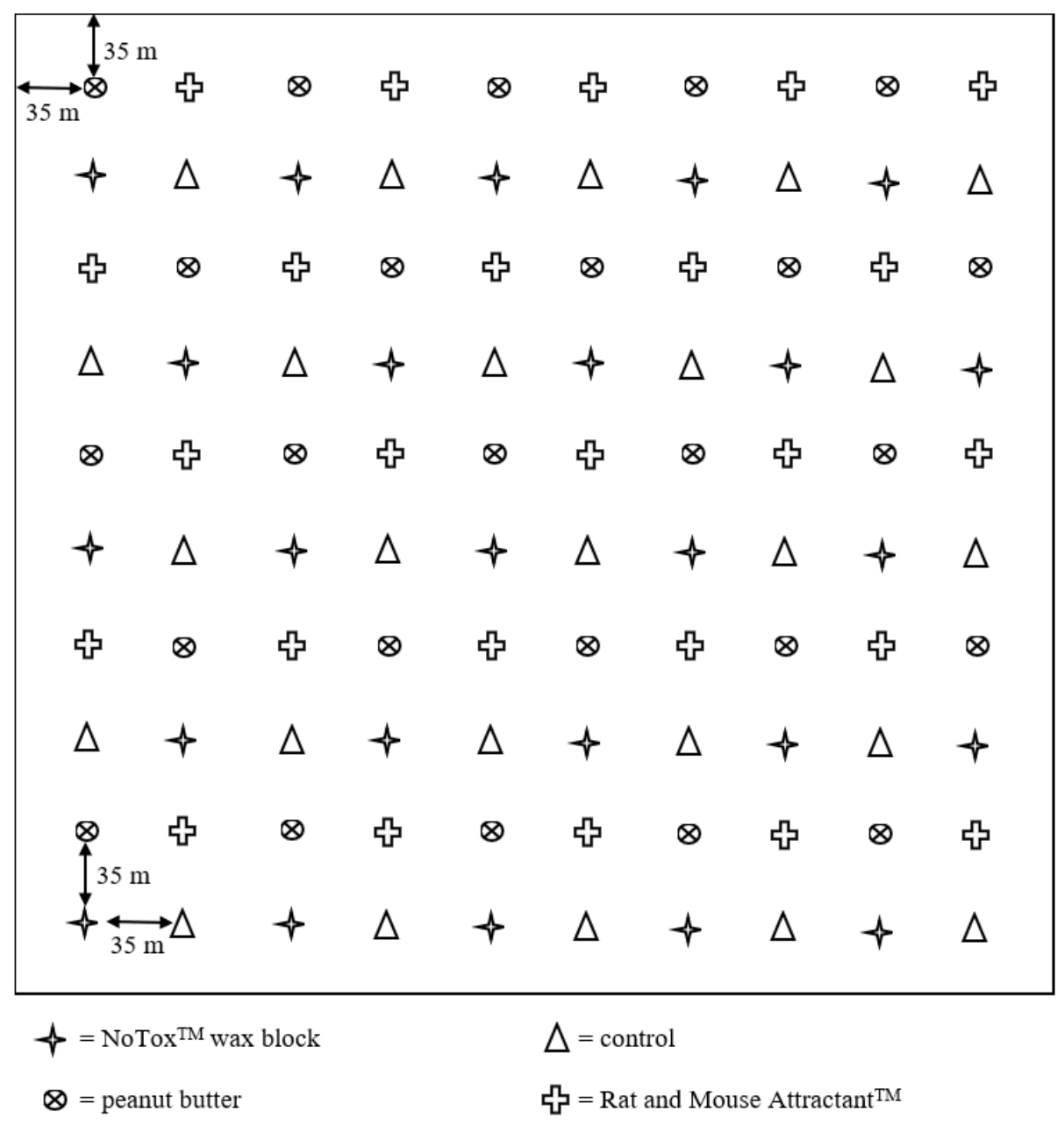

Figure 1. Example of plot layout $(385 \mathrm{~m} \times 385 \mathrm{~m})$ illustrating how tracking tunnels containing one of three attractants or a control were distributed throughout each study plot in citrus orchards in the southern San Joaquin Valley, California during winter through early spring 2020-2021. Attractants were distributed following a stratified sampling approach, thereby ensuring that no adjacent tunnels contained the same attractant; the order of attractants was determined randomly for each study plot. Outer lines of tracking tunnels were placed approximately $35 \mathrm{~m}$ from the edge of each plot, and the distance between each adjacent tracking tunnel was approximately $35 \mathrm{~m}$.

Once tracking tunnels were baited, we secured them to a $0.9-\mathrm{m}$ length of $5.1 \times 10.2-\mathrm{cm}$ wooden board using plastic cable ties, and we placed them in trees, generally 1-2 m aboveground depending on where branches provided a natural brace for the boards. Each tracking tunnel at a particular site was baited on the same day and operated for three days. At the completion of the three-day period, we checked the cards for the presence or absence of roof rat tracks. All tracking activities for this project were approved by the University of California, Davis' Institutional Animal Care and Use Committee (protocol no. 22108).

We used the Cochran-Mantel-Haenszel test $[18,19]$ to determine differences in visitation rates based on the different attractants while accounting for potential site variability. Because we tested four different attractants instead of only two, we could not use the Breslow-Day test to assess homogeneity across study sites [20]. Instead, we tested for homogeneity across our study sites using PROC CATMOD, which allowed us to fit a loglinear model to test for three-way interactions across sites, attractant types, and visitations using a likelihood ratio test [20]. If we observed homogeneity across sites but found a 
significant difference in visitation rates to the tested attractants, we combined data for each attractant for all sites. We then used Fisher's exact test to determine which attractants resulted in a higher rate of visitation [21]. We conducted analyses using SAS version 9.4 (SAS Institute Inc., Cary, NC, USA).

\section{Results}

We observed substantial visitation across all attractant categories, with mean proportions of tunnels visited in a range of $44-57 \%$ (Figure 2 ). We observed a difference in the proportion of tunnels visited across attractant groups $\left(\chi^{2}{ }_{3}=7.0 ; p=0.072\right)$, but results did not vary across our study sites $\left(\chi^{2} 15=18.6 ; p=0.234\right)$. Roof rats visited tunnels baited with wax blocks (Fisher's exact test $p=0.027$ ) and peanut butter (Fisher's exact test $p=0.036$ ) more than control plots. Roof rats also visited tracking tunnels baited with soft baits at a marginally higher rate than control tunnels (Fisher's exact test $p=0.0998$ ). We did not observe a difference in visitation between any of the attractants (Fisher's exact test $p \geq 0.721$ ), suggesting that all attractants were equally effective.

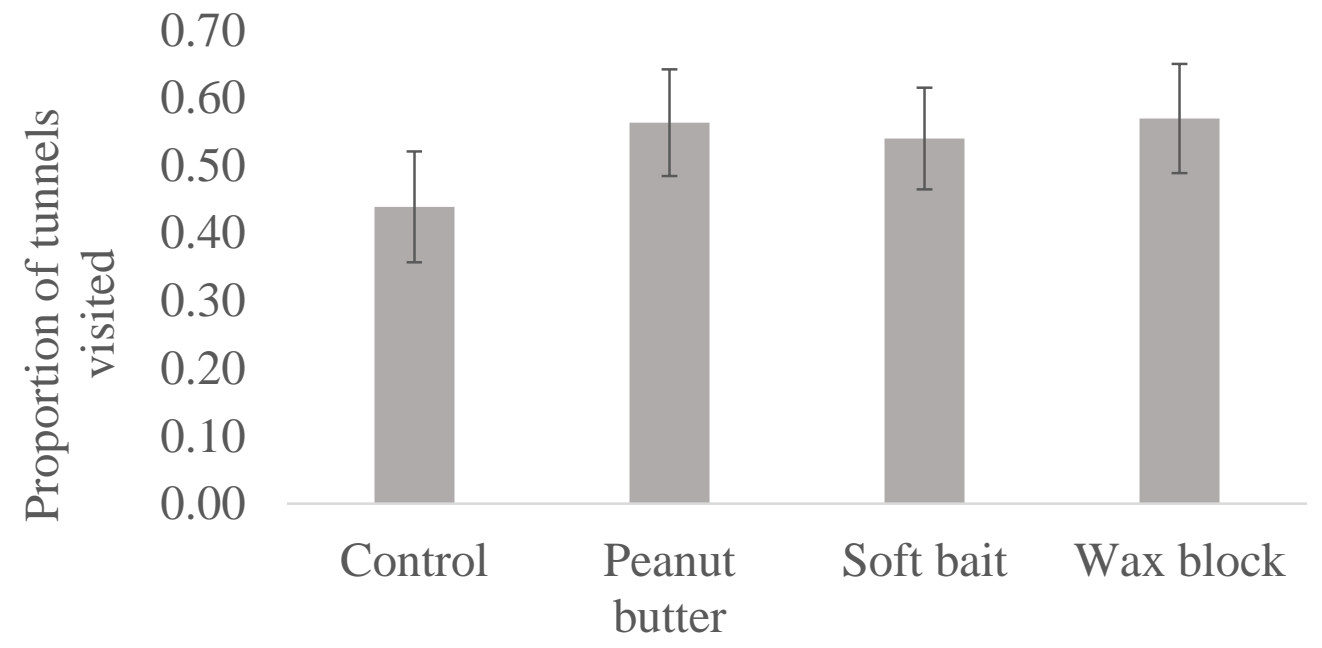

Figure 2. The mean proportion of tracking tunnels that were visited by roof rats that were baited with peanut butter, Rat and Mouse Attractant ${ }^{\mathrm{TM}}$ soft bait, NoTox ${ }^{\mathrm{TM}}$ wax blocks, or that served as a control (i.e., no bait applied) within six citrus orchards in the southern San Joaquin Valley, California, during winter through early spring 2020-2021. Standard error bars are also provided.

\section{Discussion}

Efficient and efficacious monitoring strategies are essential for the effective management of rodents in agricultural fields, with most monitoring strategies reliant upon a bait or lure to attract rodents to the monitoring device. Identifying effective attractants for rats has been researched on several occasions. Successful attractants have included rat feces, foods high in fats, and various odor attractants $[3,17,22,23]$. However, the effectiveness of these attractants has not been addressed for orchard systems, and these studies have generally not identified attractants that were readily available for use by agricultural producers. In our study, wax blocks, soft baits, and peanut butter were equally effective at attracting roof rats. Wax blocks have often proven effective at attracting various rat species in different settings $[12,24,25]$. The use of soft baits has increased in recent years, although most research into their use has occurred in commensal settings [15,23,25]. Both are commercially available, providing easy access for agricultural producers and pest control specialists. In addition, their uniform size allows for a comparison of the amount of the attractant that has been removed as an alternative measure of rodent activity $[10,14]$, although this approach has not always proven effective for roof rats in orchard systems [12]. Regardless, the potential to use these attractants to monitor rodent activity in multiple ways may make them a preferred tool for researchers. Peanut butter is also a commonly used and effective attractant [26], and it is cheaper and more easily obtained than commercial baits, likely 
increasing its utility as a roof rat attractant for agricultural producers. Given that all three were equally attractive to roof rats in citrus orchards, practicality and cost effectiveness will likely be the overriding factors to consider when deciding which attractant to use. It bears noting that citrus trees are evergreen and generally have fruit on them year-round. As such, we anticipate that these attractants would work equally well throughout the year.

Although all three products were attractive, other studies have shown attractants that incorporate semiochemicals to be superior to commonly used attractants $[17,23,27]$. For example, Takács et al. [23] developed an attractant using multiple volatile chemicals that was superior to other commercially available options for rats and mice, while Jackson et al. [27] identified single semiochemicals that outperformed the attractiveness of peanut butter. Such attractants may have substantial utility in orchards, but until they become readily available, the options we tested are more practical.

In contrast to Paull et al. [26], we determined that non-baited tracking tunnels were also attractive to roof rats. Likewise, Baldwin and Meinerz [28] noted greater visitation to tracking tunnels than to remote-triggered camera sites, and Witmer et al. [22] determined that den boxes were far more attractive to roof rats than any other attractant they investigated. Likely, the presence of a tracking tunnel in a given area is by itself highly attractive given that it provides a secure location. Collectively, this suggests that the use of tracking tunnels may yield greater detection capabilities than when using an attractant alone (e.g., with remote-triggered cameras), although this would need to be specifically tested to verify. Regardless, all three food-based lures we tested increased the attractiveness of tracking tunnels, and any could be used to increase visitation to these monitoring devices.

At our study sites, roof rats were the primary species detected with elevated tracking tunnels. Deer mice (Peromyscus spp.) were also found in citrus orchards, although very few were detected in trees. That said, deer mice are commonly arboreal in other orchard systems in the western U.S. [12], so it would be interesting to explore how these attractants compare for this pest species. Likewise, roof rats and other rat species cause extensive damage in tree crops throughout the world $[7,8,29]$. It is likely that the food-based lures we tested in this study would be attractive to those species and in those cropping systems as well, although this would need to be verified, as rodents often respond differently to monitoring tools in different crops, regions, and across species [30]. Our study should provide a useful template for other such investigations.

Author Contributions: Conceptualization, R.A.B.; data curation, K.N.W. and R.M.; formal analysis, R.A.B.; investigation, K.N.W. and R.A.B.; methodology, K.N.W., R.M. and R.A.B.; project administration, R.A.B.; resources, R.A.B.; supervision, R.M. and R.A.B.; validation, R.A.B., visualization, R.A.B.; writing-original draft, K.N.W.; writing-review and editing, K.N.W., R.M., and R.A.B. All authors have read and agreed to the published version of the manuscript.

Funding: This research received no external funding.

Data Availability Statement: Raw data are available upon request to Roger Baldwin. Data have not been archived in a repository.

Acknowledgments: We thank Liphatech, Inc. for providing attractants for this study. We also thank multiple producers and ranch managers for access to the study orchards.

Conflicts of Interest: The authors declare no conflict of interest.

\section{References}

1. Pimentel, D. Environmental and economic costs of vertebrate species invasions into the United States. In Managing Vertebrate Invasive Species, Proceedings of an International Symposium, Fort Collins, CO, USA, 7-9 August 2007; Witmer, G.W., Pitt, W.C., Fagerstone, K.A., Eds.; US Department of Agriculture, Animal and Plant Health Inspection Service, Wildlife Services, National Wildlife Research Center: Fort Collins, CO, USA, 2007; pp. 2-8.

2. Marsh, R.E. Roof rats. In Prevention and Control of Wildlife Damage, 4th ed.; Hygnstrom, S., Timm, R., Larsen, G., Eds.; Cooperative Extension Division, University of Nebraska: Lincoln, NE, USA, 1994; pp. B-125-B-132.

3. Witmer, G.; Burke, P.; Jojola, S. An evaluation of the effectiveness of potential Norway rat attractants. Proc. Vertebr. Pest. Conf. 2008, 23, 35-38. 
4. Meerburg, B.G.; Singleton, G.R.; Kijlstra, A. Rodent-borne diseases and their risks for public health. Crit. Rev. Microbiol. 2009, 35, 221-270. [CrossRef] [PubMed]

5. Buckle, A.P.; Smith, R.H. Rodent Pests and Their Control, 2nd ed.; CAB International: Wallingford, UK, 2015.

6. Worth, C.B. Field and laboratory observations on roof rats, Rattus rattus (Linnaeus), in Florida. J. Mammal. 1950, 31, $293-304$. [CrossRef]

7. Tobin, M.E. Rodent damage in Hawaiian macadamia orchards. Proc. Vertebr. Pest. Conf. 1992, 15, $272-276$.

8. Dongol, E.M.A.; Abdel Samad, M.A.; Ali, M.K.; Baghdadi, S.A.S. Estimation of damage caused by rodents on orange and mandarin orchards at Sohag governorate, Egypt. Arch. Agric. Sci. J. 2021, 4, 14-20. [CrossRef]

9. Witmer, G.W. Perspectives on existing and potential new alternatives to anticoagulant rodenticides and the implications for integrated pest management. In Anticoagulant Rodenticides and Wildlife; van den Brink, N.W., Elliott, J.E., Shore, R.F., Rattner, B.A., Eds.; Springer: Cham, Switzerland, 2018; pp. 357-378.

10. Whisson, D.A.; Engeman, R.M.; Collins, K. Developing relative abundance techniques (RATs) for monitoring rodent populations. Wildl. Res. 2005, 32, 239-244. [CrossRef]

11. Witmer, G.W.; Boyd, F.; Hillis-Starr, Z. The successful eradication of introduced roof rats (Rattus rattus) from Buck Island using diphacinone, followed by an irruption of house mice (Mus musculus). Wildl. Res. 2007, 34, 108-115. [CrossRef]

12. Baldwin, R.A.; Quinn, N.; Davis, D.H.; Engeman, R.M. Effectiveness of rodenticides for managing invasive roof rats and native deer mice in orchards. Environ. Sci. Pollut. Res. 2014, 21, 5795-5802. [CrossRef] [PubMed]

13. Shiels, A.B.; Bogardus, T.; Rohrer, J.; Kawelo, K. Effectiveness of Snap and A24-Automated traps and broadcast anticoagulant bait in suppressing commensal rodents in Hawaii. Hum. Wildl. Int. 2019, 13, 226-237.

14. Engeman, R.M.; Baldwin, R.A.; Stetson, D.I. Guiding the management of an agricultural pest: Indexing abundance of California meadow voles in artichoke field. Crop. Prot. 2016, 88, 53-57. [CrossRef]

15. Sked, S.; Abbar, S.; Cooper, R.; Corrigan, R.; Pan, X.; Ranabhat, S.; Wang, C. Monitoring and controlling house mouse, Mus musculus domesticus, infestations in low-income multi- family dwellings. Animals 2021, 11, 648. [CrossRef]

16. Brown, K.P.; Moller, H.; Innes, J.; Alterio, N. Calibration of tunnel tracking rates to estimate relative abundance of ship rats (Rattus rattus) and mice (Mus musculus) in a New Zealand forest. N. Z. J. Ecol. 1996, 20, 271-275.

17. Jackson, M.; Hartley, S.; Linklater, W. Better food-based baits and lures for invasive rats Rattus spp. and the brushtail possum Trichosurus vulpecula: A bioassay on wild, free-ranging animals. J. Pest. Sci. 2016, 89, 479-488. [CrossRef]

18. Cochran, W.G. Some methods of strengthening the common $\chi^{2}$ tests. Biometrics 1954, 10, 417-451. [CrossRef]

19. Mantel, N.; Haenszel, W. Statistical aspects of the analysis of data from retrospective studies of disease. J. Natl. Cancer Inst. 1959, 22, 719-748. [PubMed]

20. Lai, G.P.; Mink, D.R.; Pasta, D.J. Beyond Breslow-Day: Homogeneity across $\mathrm{R} \times$ C Tables. 2011. Available online: https: / / lexjansen.com/wuss/2011/analy/Papers_Lai_G_74949.pdf (accessed on 23 February 2021).

21. Zar, J.H. Biostatistical Analysis, 4th ed.; Prentice-Hall: Upper Saddle River, NJ, USA, 1999.

22. Witmer, G.W.; Snow, N.P.; Moulton, R.S. Time allocation to resources by three species of rats (Rattus spp.) in a radial arm maze. Wildl. Res. 2020, 47, 25-33. [CrossRef]

23. Takács, S.; Musso, A.E.; Gries, R.; Rozenberg, E.; Borden, J.H.; Brodie, B.; Gries, G. New food baits for trapping house mice, black rats and brown rats. Appl. Anim. Behav. Sci. 2018, 200, 130-135. [CrossRef]

24. Thomas, M.D.; Brown, J.A.; Henderson, R.J. Feasibility of using wax blocks to measure rat and possum abundance in native forest. Proc. N. Z. Plant Prot. Conf. 1999, 52, 125-129. [CrossRef]

25. Burke, C.B.; Quinn, N.M.; Stapp, P. Use of rodenticide bait stations by commensal rodents at the urban-wildland interface: Insights for management to reduce nontarget exposure. Pest. Manag. Sci. 2021, 77, 3126-3134. [CrossRef] [PubMed]

26. Paull, D.J.; Claridge, A.W.; Barry, S.C. There's no accounting for taste: Bait attractants and infrared digital cameras for dectecting small to medium ground-dwelling mammals. Wildl. Res. 2011, 38, 188-195. [CrossRef]

27. Jackson, M.D.; Keyzers, R.A.; Linklater, W.L. Single compounds elicit complex behavioural responses in wild, free-ranging rats. Sci. Rep. 2018, 8, 12588. [CrossRef] [PubMed]

28. Baldwin, R.A.; Meinerz, R. Developing an effective strategy for indexing roof rat abundance in citrus orchards. Crop. Prot. 2022, 151, 105837. [CrossRef]

29. Puan, C.L.; Goldizen, A.W.; Zakaria, M.; Hafidzi, M.N.; Baxter, G.S. Absence of differential predation on rats by Malaysian barn owls in oil palm plantations. J. Raptor Res. 2011, 45, 71-78. [CrossRef]

30. Engeman, R.; Whisson, D. Using a general indexing paradigm to monitor rodent populations. Int. Biodeterior. Biodegrad. 2006, 58, 2-8. [CrossRef] 